\title{
Influence of Self-Esteem on Students' Academic Performance in Secondary Schools in Tharaka Nithi County, Kenya
}

\begin{abstract}
Maasai Mara University, Kenya

The purpose of this study was to examining the influence of self-esteem on students' academic performance in secondary schools in Tharaka-Nithi County, Kenya. The study adopted the descriptive survey research design. A sample size of 340 respondents was selected. Stratified random sampling and purposive sampling technique were used to select the 301 form three student, 13 heads of curriculum, 13 deputy head-teachers and 13 heads of guidance and counseling. Data was collected using questionnaires and interview schedules. Descriptive statistics (such as frequencies, mean and standard deviation) and inferential statistics (such as Chi-square test) techniques were used to analyze data. The study found that self-esteem has no significant influence on students' academic performance in secondary schools (Chi-square $=13.92, \mathrm{df}=8, \operatorname{sig}(\mathrm{p}$-value $)=0.084)$. This implies that low or high self-esteem does not influence student's academic performance. The study recommends the need to build selfesteem among students. This will guarantee good academic performance in secondary schools. Moreover, the study recommends the need for school administration to focus on academic activities that are geared towards improving academic performance in secondary schools. It is anticipated that the findings of the current study will provide necessary information useful to the policy makers, academician, students, teachers, school administration and other stakeholders to enhance academic performance of students in secondary schools in Kenya.
\end{abstract}

Mercy Nkinga Kariuki, Fredrick Ogolla, Mwaura Kimani

Department of Education Foundation \& Psychology,

KEY WORDS: Academic performance; Low grades; Quality grades; Self-esteem; Students

DOI: $10.7176 / \mathrm{JEP} / 10-2-18$

\subsection{INTRODUCTION}

Background to the Study

Self-esteem is a life skill that is highly embraced by all societies at all stages of development. It is the process by which individuals rate themselves, acquire knowledge, skills and attitudes to enable them participate effectively in the society. According to Kholode (2009), self-esteem education somehow determines the level of prosperity, welfare and security of people. It is the cornerstone of economic, social development and a principle means of improving the welfare of individuals. In his study on the influence of self- esteem on the study habits of students in America, Miller (2002) points out that, high school learners need to accept and value themselves to do well in their academic work.

In his study on the factors influencing students' academic performance in New York, James (2004) points out that academic performance is use of one's aptitude in studying and making accomplishments and achievements in terms transfer of knowledge, communication skills negotiation skills and good grades and marks in examinations. Also, in his study on the challenges facing high school education in Tanzania, Robert (2008) emphasizes that provision of education in East Africa has been faced with numerous challenges, for instance poor academic performance among learners. Robert (2008) opines that Poor academic performance leads to students' frustration and this can lead to negative self-esteem among learners which can later impact negatively on the economy of a country. It also causes psychological suffering to parents if they have to pay more money to take their children to other schools.

According to KIE (2008), education is activated through the cognitive, psychomotor and the affective domain. The affective domain in enhanced through life skills education, self-esteem being one of the skills. The development of life skills is a life-long process that starts in early childhood and continues throughout one's life. Life skills education enables students to develop positive attitude towards self and others by transforming knowledge, skills and values into action. This enhances students' abilities to make effective decisions and relate amicably with others in society. The three major categories of life skills: skills of knowing and living with oneself that include self-awareness, self-esteem, coping with emotions and coping with stress .There is the skill of knowing and living with others and that of making effective decisions. Where life skills education is well developed and practiced it can enhance the well being of society and promote positive outlook and healthy behaviour among learners (KIE, 2006). 
Self-esteem is the value an individual places on themselves relative to others. It is also what one believes and feels about themselves. It can also mean accepting one's weaknesses as well as strengths, and that one feels that they deserve the respect from others. With self-esteem, one learns to build on strengths and to compensate for weaknesses. A positive self-esteem is crucial in maintaining academic performance among students (Mutuma, 2007).

KIE (2008) defines academic performance as all activities academic in nature including examinations. The academic performance in KCSE of secondary students in Tharaka-Nithi County has registered a decline for some years, hence, the need for this study, to explore the influence of self-esteem on students' academic performance in KCSE in secondary schools in Tharaka-Nithi County, Kenya.

A person's self-esteem can be perceived as negative or positive depending on how one evaluates their worth (Dondo, 2005). The value that one attaches to self leads to the level of self-esteem that they have. As a result, this level of self-esteem can influence ones performance of tasks in various situations in life. The two extremes of self-esteem are not desirable. Positive self-esteem implies that, comparing ones value to others, the individuals find themselves superior. This can lead to behaviours like arrogance, selfishness and difficult in coping with others. Such behaviour may influence an individual's academic performance.

Academic performance in KCSE of secondary school students in Kenya has registered a decline for a number of years. Tharaka Nithi has not been an exception compared to other counties like Meru, Embu, Isiolo and Marsabit. According to County Director's office, in 2016, Tharaka-Nithi County had only 9\% of its KCSE candidates joining the regular university programme. This performance was way below Meru County which had 16\%, Embu 15\%, Marsabit 12\%and Isiolo 14\%.

Mugambi (2010) in his study found that students with positive self-esteem can perform well academically if the right environment is presented. However, majority of these studies centered on the cognitive aspects of the learner and instructions and methods used by the teachers in teaching, ignoring the affective domain of the learner. Research has shown that enhancing the self-esteem of students is a critical goal and is a means of facilitating attainment of desirable outcomes in education such as academic effort and persistence in tasks. There is need to understand the influence of students' self-esteem on academic performance.

Previous studies have addressed the relationship between discipline and student's academic performance in secondary's schools by gender. Also, the past studies have examined the influence of head of curriculum level of self-esteem and academic performance in secondary schools. These studies did not address the influence of selfesteem on students' academic performance using inferential statistics (chi-square analysis). This is what the current study intended to address. The study therefore seeks to determine the influence of students' self-esteem on academic performance in secondary schools in Tharaka-Nithi County in attempt to fill the gap.

\subsection{LITERATURE REVIEW}

\subsection{Self-esteem and Students Academic performance}

Greeno (2001) notes that self-esteem is always attributed to best performances in tasks and at work place. Selfvalue may strengthen the learners' relationship with the facilitator. This implies that the students may benefit more from the teacher due to the free atmosphere. It also reduces problems like; truancy, absenteeism, drug and substance abuse and teenage pregnancies that are known to cause poor performances. Character building emanate from self-esteem. Students with self-esteem are able to manage and use their leisure time well. Moreover, they are able to choose good and reliable friends who can help in boosting their academic performance, (K.I.E, 2008). Self-esteem is ones emotional evaluation of worth or judgment of one's self attitude. Students with positive self-esteem are good at negotiation skills with others. They respect others opinion and listen to others views. They also have many friends for they embrace non-violent behaviour in solving conflicts (UNESCO, 2000).

According to Dondo (2005), such students relate well with teachers and this can assist them make consultations in case of challenges in academic work as well as tackle assignments in good time. They take failure in examinations as a stepping stone to success. This implies that they work harder to improve whenever they do not perform well. When criticized by colleagues and teachers they take the criticisms positively. They have good interpersonal relationships (Petro, 2000). They excel in academic performance and recognize the role played by others in the same. When they deviate in discipline they are easily corrected. As students they dress well and decently always and not many teachers who raise complaints about their dressing code. Their academic 
discussions are harmonious and always labour to live in peace with colleagues. They are not overconfident about their knowledge and intelligence (Ongoma, 2008). The result of this is improvement in academic performance.

Heaven (2005) says that self-esteem has become a household word. Teachers, parents, therapists, and others have focused efforts on boosting self-esteem, on the assumption that positive self-esteem will cause many positive outcomes and benefits-an assumption that is critically evaluated in this study. Appraisal of the effects of self-esteem is complicated by several factors. Because many people with positive self-esteem exaggerate their successes and good traits, we emphasize objective measures of outcomes. Positive self-esteem is also a heterogeneous category, encompassing people who frankly accept their good qualities along with narcissistic, defensive, and conceited individuals. He notes that the modest correlations between self-esteem and school performance do not indicate that positive self-esteem leads to good performance. Instead, positive self-esteem is partly the result of good school performance. Efforts to boost the self-esteem of pupils have not been shown to improve academic performance and may sometimes be counterproductive. Job performance in adults is sometimes related to self-esteem, although the correlations vary widely, and the direction of causality has not been established. Occupational success may boost self-esteem rather than the reverse. This means that good academic performance in KCSE may boosts self-esteem and not the vice versa.

In his study on the relationship between intellectual ability and excellence in academic performance in America, Shulman (2012) notes that there is little or no relationship between intellectual ability and academic excellence. Mutuma (2007), in his study conducted in Nigeria on the influence of discipline in academic performance says that one's discipline is crucial in determining academic excellence. Another research on the effects of selfesteem on student's academic achievement in Zambia by Akujohi (2006) points out that the level of self-efficacy among learners affects their academic performance, in that the higher the efficacy the better the performance.

Another research examining the role of self- efficacy in learners academic performance by Akujoji (2006) states that the higher the efficacy the better the performance of students. This research tends to agree that positive selfesteem can lead to better academic performance while negative self-esteem may lead to mediocre or dismal performance among learners. None of the studies above has examined the Influence of self-esteem on students academic performance hence it is significant to conduct this research in Tharaka-Nithi County.

In her study of the effectiveness of the heads of curriculums' level of self-esteem on the students' K.C.S.E performance in Kiambu, Susan Wangechi (2009) points out that the more confidence heads of curriculum have the better they are able to run the school and the better the students results. This idea of Susan (2009) is contrasted by Joan (2011) in her study of the relationship between leadership styles and student's academic performance. Joan (2011) points out that academic performance in KCSE is not influenced by the way the heads of curriculums rate themselves. This implies that one's level of confidence does not affect their performance of duty. Hence self-esteem whether low or high does not affect learners' academic performance. This shows that the current study can be used to establish whether self-esteem influences students' academic performance or not.

Dondo (2005) observes that self-esteem may be helpful only in some job contexts. Laboratory studies have generally failed to find that self-esteem causes good task performance, with the important exception that positive self-esteem facilitates persistence after failure. People high in self-esteem claim to be more likable and attractive, to have better relationships, and to make better impressions on others than people with negative self-esteem, but objective measures disconfirm most of these beliefs. Narcissists are charming at first but tend to alienate others eventually. Self-esteem has not been shown to predict the quality or duration of relationships.

Guindon (2002) comments that positive self-esteem makes people more willing to speak up in groups and to criticize the group's approach. Leadership does not stem directly from self-esteem, but self-esteem may have indirect effects. Relative to people with negative self-esteem, those with positive self-esteem show stronger ingroup favoritism, which may increase prejudice and discrimination. He continues to point out that neither high nor negative self-esteem is a direct cause of violence. Narcissism leads to increased aggression in retaliation for wounded pride. Negative self-esteem may contribute to externalizing behaviour and delinquency, although some studies have found that there are no effects or that the effect of self-esteem vanishes when other variables are controlled. The highest and lowest rates of cheating and bullying are found in different subcategories of positive self-esteem .Hence the need for this study.

According to Rosenberg (2001) self-esteem has a strong relation to happiness. Although the research has not clearly established causation, we are persuaded that positive self-esteem does lead to greater happiness. Negative self-esteem is more likely than high to lead to depression under some circumstances. Some studies support the 
buffer hypothesis, which is that positive self-esteem mitigates the effects of stress, but other studies come to the opposite conclusion, indicating that the negative effects of negative self-esteem are mainly felt in good times. Still others find that high self- esteem leads to happier outcomes regardless of stress or other circumstances.

Silverstone (2003) noted that positive self-esteem does not prevent children from smoking, drinking, taking drugs, or engaging in early sex. If anything, high self- esteem fosters experimentation, which may increase early sexual activity or drinking, but in general effects of self-esteem are negligible. One important exception is that positive self-esteem reduces the chances of bulimia in females. This shows that self-esteem whether high or low may not prevent misbehaviour among students. Viktor (2012) highlights that the benefits of positive self-esteem fall into two categories: enhanced initiative and pleasant feelings. We have not found evidence that boosting selfesteem (by therapeutic interventions or school programs) causes benefits. Our findings do not support continued widespread efforts to boost self-esteem in the hope that it will by itself foster improved outcomes. In view of the heterogeneity of positive self-esteem, indiscriminate praise might just as easily promote narcissism, with its less desirable consequences. Instead, we recommend using praise to boost self-esteem as a reward for socially desirable behaviour and self-improvement.

Douglas (2010), notes that teachers and parents favor the smartest or the cleverest students in schools. All the others feel like failures. Douglas (2009) continues to say that the so-called curve grading system is wrong. Equally wrong is the idea of segregating students into different classrooms according; to their aptitude and performance. Grades should be based on the ability to master course, discipline applied in study habits and the development of a high level self-esteem that will enable the students to go on to further achievements. A student, who fails even once and is not given adequate support by the teacher, may develop negative self-esteem and may not try again. A teacher should never tell a student that he/she is stupid or dump. Instead, he should challenge him/her to do his/her best in academic work. Tharaka-Nithi County has also portrayed poor academic performance in KCSE in the last five years. In this research, poor academic performance in KCSE implies scoring a mean grade of $\mathrm{C}$ plain and below while good performance means scoring a mean grade of $\mathrm{C}$ plus and above that enable one to pursue university education. This implies that majority of students do not qualify for degree courses hence the need to establish the Influence of self-esteem on academic performance among secondary school students in Tharaka-Nithi County. The following Table 1 shows academic performance in KCSE in the four sub-counties.

Table 1: $\underline{\text { K.C.S.E Performance in Tharaka-Nithi County }}$

\begin{tabular}{llllll}
\hline Sub-county & 2016 & 2015 & 2014 & 2013 & 2012 \\
\hline Maara & $41 \mathrm{C}-$ & $40 \mathrm{C}-$ & $42 \mathrm{C}-$ & $37 \mathrm{D}+$ & $35 \mathrm{D}+$ \\
Chuka Igamba Ng'ombe & $39 \mathrm{D}+$ & $41 \mathrm{C}-$ & $35 \mathrm{D}+$ & $35 \mathrm{D}+$ & $30.2 \mathrm{D}$ \\
Tharaka North & $30 \mathrm{D}$ & $29.2 \mathrm{D}-$ & $31.4 \mathrm{D}$ & $28 \mathrm{D}-$ & $27.9 \mathrm{D}-$ \\
Tharaka South & $31 \mathrm{D}$ & $22.4 \mathrm{D}$ & $26.6 \mathrm{D}-$ & $36.1 \mathrm{D}+$ & $29.9 \mathrm{D}$ \\
Tharaka-Nithi County & $35.2 \mathrm{D}+$ & $33.2 \mathrm{D}$ & $34.0 \mathrm{D}$ & $34.0 \mathrm{D}$ & $30.6 \mathrm{D}$ \\
\hline
\end{tabular}

Source: TSC County Director's office, 2016

\subsection{Theoretical Framework}

A theory is a coherent set of ideas that helps to explain data or phenomenon and to make predictions. It is a set general statement (rules, assumptions, propositions or principles) used to explain facts (Meece 2002). A theory consists of hypothesis or assumptions that can be tested to determine the accuracy (Santrock 2010).

\subsubsection{Vigotsky's Social-cultural Theory}

Vigotsky (2002) notes that this theory emphasizes on the significance of cooperative or supported learning. According to the theory, every child has some knowledge and builds on the same through the support they get from peers and adults. This means that students can improve on their self-esteem, modify discipline and improve their academic performance with the support they get from those who are more skilled in the society. The theory emphasizes the importance of play, dialogue between teacher and student, cooperative learning, joint problem solving, coaching, mentoring and assisted learning. He argued that children's experiences are extended through interactions with adults and peers. The child grows and changes as a function of his/her efforts and support, guidance and help from others who are more skilled Vygotsky (2002). Social groups have an important effect on children's knowledge and understanding the world. He believed that children can attempt more complex tasks if they had the support from others. The child's ability can be stretched with the help of another 
person. He called this the zone of proximal Development (ZPD) or the next area of development which could only be achieved with the help and support of others. Vygosky $(2002,43)$ argued for cooperative or supported learning. This theory is applicable in the study in that learners' mental ability and social development is supported and enhanced by others through social interaction. The school is used for socialization and in the process of socialization learners benefit a lot from peers and adults, who are teachers. This supported learning can assist learners in their academic performance. The dialogue between the teachers and learners helps students 'scaffold' that is develop new concepts and think of higher level concept. The child can use learning institution, cooperative learning, joint problem solving, coaching mentoring and assisted learning are in agreement with Vygosky's theory. This theory shows how students who are supported by parents, teachers and peers build their self-esteem that may impact on their academic performance positively.

\subsubsection{Abraham Maslow's Hierarchy of Needs}

Abraham Maslow's hierarchy of needs is among the theories of motivation known as content and process theories. Maslow, Alderfer, Herzberg and Mc eel land (2009) point out that behaviour is as a result of motivation. Herzberg (2004) says that there are two factors that affect ones motivation, that is, hygiene factors and motivators. A series of hygiene factors creates dissatisfaction if individuals perceive them as inadequate or inequitable, yet individuals will not be significantly viewed as adequate or good. Hygiene factors are extrinsic and include factors such as, provision of basic needs that is, food shelter, clothing, salary or remuneration, job security and working conditions. Motivators are intrinsic factors such as sense of achievement, recognition, responsibility and personal growth. So, if students basic needs are met they will feel motivated to work towards boasting their self-esteem that can lead to improvement of academic performance.

According to Maslow (2003) individuals strive to seek higher needs when lower needs are fulfilled. Once a lower need is satisfied, it no longer serves as a source of motivation. Needs are motivators only when unsatisfied .In the first level, Maslow has physiological needs which include the most basic needs for human beings to survive, such as water, food and shelter. This means that if students basic needs are meet they can develop selfesteem and hence improve their academic performance. The second level has safety needs which include personal security, good health, well-being and safety against accidents. This again shows how this theory informs on the current study that when students' security is provided they can build self confidence that can make them behave well and value themselves leading to good academic performance. In the third level, belonging needs exist. Students need to feel a sense of belonging and acceptance in their families and school. So the way parents and teachers relate with their children and students, can affect their level of self-esteem and hence affect their academic performance in secondary school in Tharaka-Nithi County, Kenya

Similarly, according to Dondo (2005) students who relate well with their teachers easily build confidence and this can assist them to have self-integrity which is crucial in character building. So, a sense of belonging and acceptance are pivotal in building students behavior. The fourth level denotes self-esteem needs. This is where people look to be respected and to have self-respect .learners in this level desire to achieve and respect others. This assists the current study in that when students have self-esteem they can easily respect others hence depicting good character. They work to live in harmony and shun conflicts. In the top level, self-actualization needs remain. This level of needs pertains to realizing the person's potential. Dismal academic performance may hinder students from getting motivated to high needs in Maslows' hierarchy of needs. The hierarchy of needs pyramid is illustrated in Figure 1

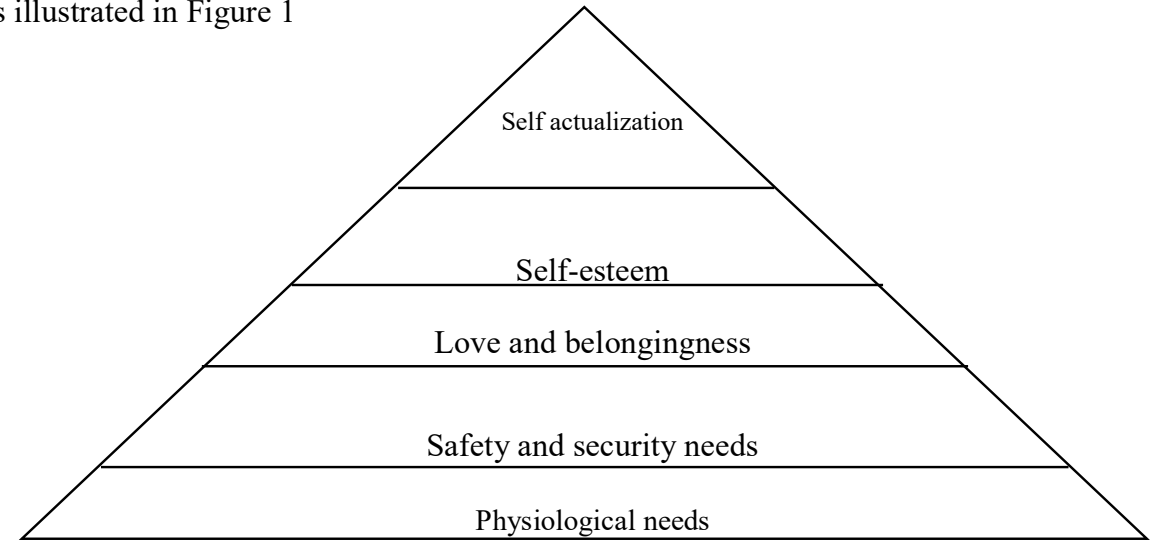

Figure 1: Maslows' hierarchy of needs 
Gichinga (2010) points out that many people including students have tried to place themselves on the one of the five levels of the pyramid. This may be an easy task for some, but many struggle in the ups and downs of life. For many students life and particularly in and out of school especially those with indiscipline cases and perform dismally in academics find it a challenge to get to the top of the pyramid. They often have one foot on one level and the other foot on the next level and are reaching out at times trying and pulling themselves up while making sure they don't fall backwards. As people climb the pyramid they often make a head way but also notice that two steps forward can mean one step backward. The goal of mankind is to keep an eye on the top of the pyramid and to climb as steadily as possible.

According to Branden (2009) Students may stumble at times and leap forward at times depending on the level of academic performance. Those whose self-esteem is positive may find it easy to get to top. No matter how far they fall backward, students require support systems to help them reach the highest needs in their life. So, according to Maslow students' needs are in hierarchy. They can only aspire for the needs in the upper level if those in the lower level are fulfilled. Students have basic needs like food, shelter and clothing. These are the basic needs in their life and if they are satisfied they aspire for the needs in the next level that is, safety needs. When the physiological, the safety and the love and belonging needs are met the students long for self-esteem this implies the feeling of being accepted as worthwhile and valuable in what they do. If they are not appreciated they may end up being disobedient in schools hence, the need for the current study to examine the influence of self-esteem on students' academic performance.

\subsection{Conceptual Framework}

Mouly (2013) explains that a conceptual framework is graphic diagram of a research topic or thesis. It enables the researcher to find links between the existing literature and his/her own research goals. Researchers use it to guide in data collection and analysis. Diagrammatically the relationships among the variables are represented in Figure 2

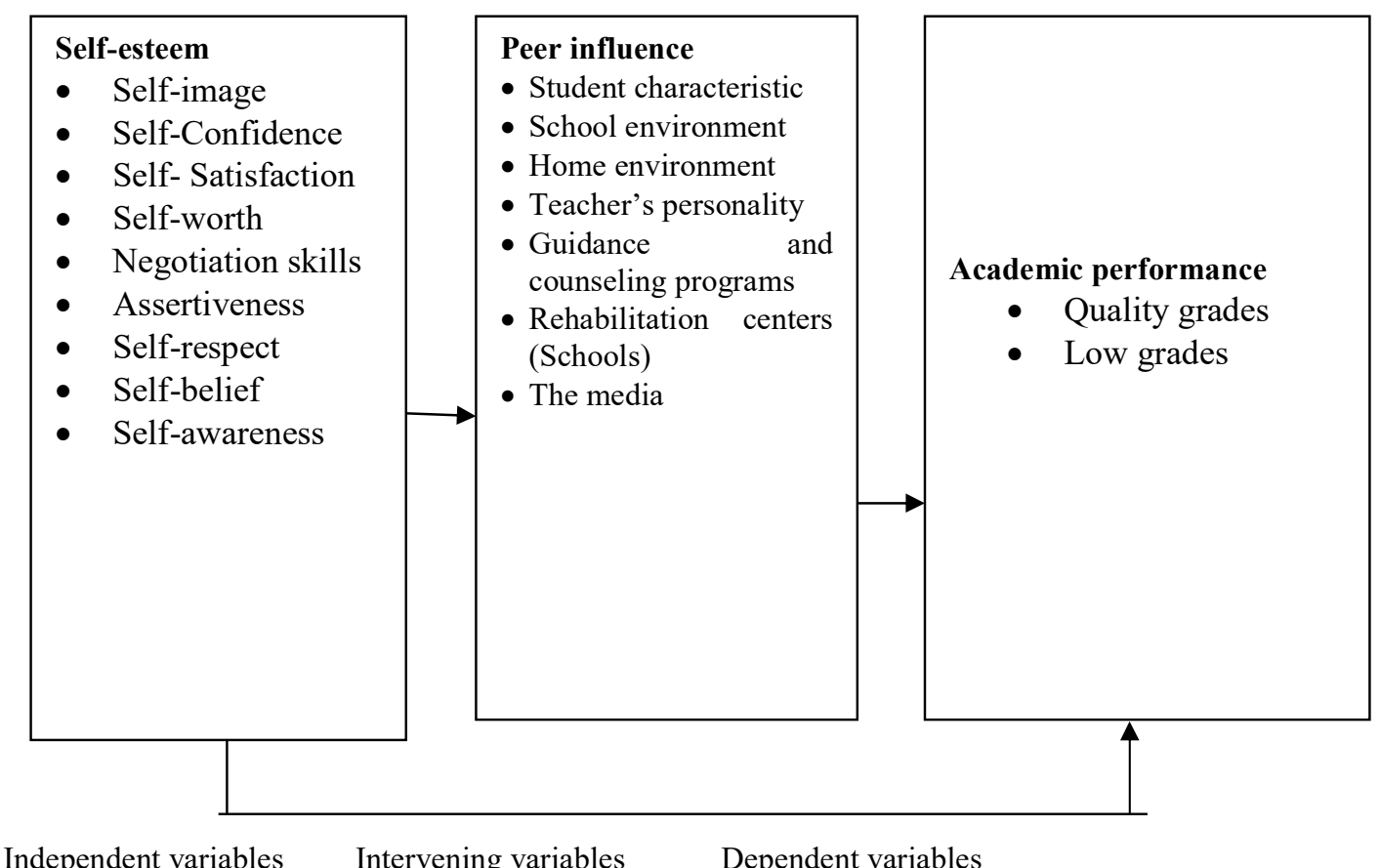

Figure 2: Influence of Self-esteem on Students' Academic performance in Secondary Schools in Tharaka-Nithi County, Kenya.

\subsection{RESEARCH DESIGN AND METHODOLOGY}

\subsection{Research Design}

The study used descriptive survey research design. Orodho and Kombo (2002), explains that a descriptive survey research design involves collecting data in order to test hypotheses or answer questions concerning the 
current status of the subject under study. Descriptive survey research design was preferred due to its appropriateness in obtaining opinions, believes and attitudes from a large population in order to establish one or more population parameters. It deals with collection of original data from a population that is too large to be observed directly. It collects information from a sample that is representative of the population as a whole. This design is cost effective and the results can be generalized to the population (Orodho, 2004). The descriptive research design was suitable for the study because it enabled the researcher to gather data from a wide range of respondents and to determine and report the way things are at present.

\subsection{Sampling Procedures and Sample Size}

Kombo and Tromp (2006) observed that stratified random sampling involves dividing the population into homogenous sub groups and then taking a simple random sample in proportion to their numbers in the population. Once this was done guidelines by Kathuri and Pals (1993) were used in selecting representative sample of 301 students (10\%). Deputy principal's, heads of curriculum and heads of guidance and counseling were purposively selected. The total sample size was 340 respondents as indicated in Table 2

Table 2: Students' Enrolment Sample by School Category

\begin{tabular}{lccccccc}
\hline Schools Category & \multicolumn{2}{c}{ Students } & TC & D/HT & & HC & Total n \\
\cline { 2 - 3 } & Males & Females & & & & & \\
\hline National & 69 & 61 & 1 & 1 & 1 & 133 \\
Extra county & 30 & 30 & 5 & 5 & 5 & 75 \\
County schools & 45 & 35 & 5 & 5 & 5 & 95 \\
County day schools & 20 & 11 & 2 & 2 & 2 & 37 \\
Total & 164 & 137 & 13 & 13 & 13 & 340 \\
\hline
\end{tabular}

\subsection{Instrumentation}

Data was collected by use of a questionnaire for students and interview schedules for heads of guidance and counseling, heads of curriculum and deputy principals.

\subsection{Data Analysis Techniques}

The collected data was coded and analyzed using Statistical Package for Social Sciences (SPSS). Descriptive statistics that is a branch of statistics that provide a means of summarizing data (Fildmay, 1987) was used to describe the sample, independent and dependent variables (self-esteem and academic performance). For inferential statistics, the study used Chi-square test for the research hypothesis.

\subsection{RESULTS AND DISCUSSIONS}

\subsection{Respondents Response Rate}

The questionnaires administered to the students by the researcher were 301 and 39 Deputy Principals, heads of curriculum and heads of Guidance and Counseling were interviewed. However, 272 questionnaires were filled and returned and 39 interviews were conducted. This gave a response rate of $90.4 \%$. This high return rate was attributed to the method used by the researcher (hand delivery and follow up) to distribute the tools to the respondents. The analyses of the responses were as shown in Table 3

Table 3: Respondents Response Rate

\begin{tabular}{lccc}
\hline Category of school & Sample & Achieved & Response Rate (\%) \\
\hline National & 130 & 129 & $99.2 \%$ \\
Extra county & 60 & 48 & $80.0 \%$ \\
County boarding & 80 & 68 & $85.0 \%$ \\
Day schools & 31 & 27 & $87.0 \%$ \\
Total & 301 & 272 & $90.4 \%$ \\
\hline
\end{tabular}




\subsection{Students' Self-esteem}

Self-esteem is the value-judgment that a person passes on himself. The nature of ones self-evaluation has profound effects on a man's thinking- process, emotions, desires, values and goals. To understand any human being psychologically one must understand the nature and degree of his self-esteem and the standards by which he judges himself. Self-esteem is the integrated sum of self-confidence and self-respect. It is the conviction that one is competent to live and worthy of living. It is also, the single most significant key to his behaviour. There are three categories of self-esteem; high, moderate and low. The pillars of self-esteem include; the practice of living consciously, practice of self-acceptance, practice of self-responsibility, practice of self-assertiveness, practice of living purposefully and the practice of personal integrity. The study sought to establish the level of self-esteem among students' in secondary school and the findings are portrayed in Table 4.

Table 4: Descriptive Statistics on Students' Self-esteem

\begin{tabular}{llll}
\hline Students' self-esteem & $\mathrm{N}$ & Mean & SD \\
\hline Confidence level & 269 & 4.03 & .830 \\
Satisfaction with self-image & 263 & 4.23 & .812 \\
Self-value & 261 & 4.26 & .860 \\
Belief for self & 260 & 4.42 & .784 \\
Respect for self & 260 & 4.39 & .856 \\
Openness to new ideas & 266 & 3.77 & .900 \\
Self-acceptance & 257 & 4.19 & .884 \\
Feelings of adequacy & 261 & 3.72 & .904 \\
Level of assertiveness & 256 & 3.87 & .996 \\
Negotiation skills & 267 & 3.77 & 1.013 \\
Average & & 4.07 & .884 \\
\hline
\end{tabular}

The results in Table 4, shows high rating of student self-esteem in secondary schools. The overall mean score was 4.07. This implies that, the high self-esteem among students is critical in their academic undertaking in secondary schools. In a research carried out in America by Van Pelt (2011) points out that the results of positive self- esteem to learners are desirable and characterize individuals who have accepted themselves. He continues to say that students with positive self-esteem are able to live positively with what they are unable to change. Rosenberg (2008) also notes that people suffering from negative self-esteem constantly berate themselves and are not able to maintain good relationships with colleagues and teachers.

Kagoma (2006) observes that the emotional conduct of people with low self-esteem, is manifested in their being critical of others, are full of pessimism, short tempered and never plan positively for their time and resources. They may be devoid of rational character guidance and are easily addicted to alcohol and drug. According to Dondo (2005) Students' with low self-esteem are sensitive to criticism and reject assistance from others.

\subsection{Influence of Self-esteem and Students' Academic Performance}

To determine the influence of self-esteem on students' academic performance in secondary schools in Tharaka Nithi County the study adopted a chi-square test at $5 \%$ level of significance.

\subsubsection{Importance of Self-esteem on Academic Activities}

The study sought to determine the importance of self-esteem in relation to students' academic activities in secondary schools in Tharaka-Nithi County. The findings are portrayed in Table 5 
Table 5: Importance of Self-esteem on Academic Activities

\begin{tabular}{|c|c|c|c|}
\hline Importance of self-esteem on academic activities & $\mathrm{N}$ & Mean & SD \\
\hline $\begin{array}{l}\text { My confidence in school has helped me to handle group discussions with } \\
\text { other students well }\end{array}$ & 270 & 4.13 & .969 \\
\hline $\begin{array}{l}\text { My satisfaction with my self-image has assisted me to tackle assignment } \\
\text { in school without failure }\end{array}$ & 269 & 3.96 & 1.034 \\
\hline My valuing myself has assisted me to improve in academic performance & 267 & 4.02 & .957 \\
\hline $\begin{array}{l}\text { My belief in being as good as other people has assisted me to be focused } \\
\text { in my studies. }\end{array}$ & 265 & 4.16 & .948 \\
\hline $\begin{array}{l}\text { Having respect for myself has assisted me to avoid cheating in the } \\
\text { examinations }\end{array}$ & 269 & 4.39 & .894 \\
\hline My self-worth has assisted me to shun laziness in school & 269 & 4.04 & 1.010 \\
\hline $\begin{array}{l}\text { My feeling of success has assisted me to do all school assignments in } \\
\text { good time. }\end{array}$ & 265 & 3.97 & 1.113 \\
\hline My feeling of success has assisted me to be consistent in my study habits. & 262 & 3.93 & 1.057 \\
\hline $\begin{array}{l}\text { My being assertive has assisted me to stick to my academic activities' } \\
\text { schedules. }\end{array}$ & 268 & 3.87 & 1.127 \\
\hline $\begin{array}{l}\text { My good negotiation skills have assisted me to take part in interschool } \\
\text { symposiums }\end{array}$ & 269 & 3.91 & 1.250 \\
\hline Average & & 4.04 & 1.036 \\
\hline
\end{tabular}

The results in Table 5 reveal that the average mean score for importance of self-esteem in relation to academic activities was 4.04. This implies that majority of the respondents agreed that self-esteem is critical in academic matters. The respondents agreed that having respect for themselves has assisted to avoid cheating in examinations (the mean $4.39, \mathrm{SD}=0.894$ ). In addition, the respondents agreed that self confidence in school has helped them to handle group discussions with other students well (mean score 4.13, SD=0.969). In general, the respondents agreed that, self-esteem plays a critical role in academic activities in secondary schools.

\subsubsection{Students' Academic Performance}

The study sought to find out the academic mean grades scored in the end of year zonal exam and KCSE for the year 2015, 2016 and 2017. This helped the researcher to evaluate the average performance of the students. Table 6 displays the average grades achieved by the students in zonal exams for the last three years in secondary schools.

Table 6: Descriptive Statistics on Academic performance in Zonal Exams

\begin{tabular}{llllll}
\hline Mean Grade & Frequency & Percent & Year & Mean & SD \\
\hline C- & 17 & 6.3 & 2015 & 7.65 & 1.940 \\
C & 57 & 21.0 & & & 1.836 \\
C+ & 67 & 24.6 & 2016 & 7.66 & 1.817 \\
B- & 28 & 10.3 & & & \\
B & 54 & 19.9 & 2017 & 7.66 & $\mathbf{1 . 8 6 4}$ \\
B+ & 44 & 16.2 & Average & $\mathbf{7 . 6 6}$ & \\
A- & 5 & 1.8 & & & \\
Total & 272 & 100.0 & & & \\
\hline
\end{tabular}

The results in Table 6 indicate that majority (24.6\%) of the respondents attained a mean grade of $\mathrm{C}+$. In addition, $48.2 \%$ of the students attained a mean grade above $\mathrm{C}+$. This implies that almost half of the respondents had performance above average. This suggests that the students are serious with their academic work and the teaching is a top priority in the secondary schools. However, $27.3 \%$ of the respondents attained a grade below $\mathrm{C}+$. This indicates that there is need for schools administration to put in place a mechanism that would guarantee an improvement on the individual academic performance. The overall mean score of performance was 7.66 (7.66 $\approx 8$ (B-). This implies that the students had achieved the academic performance in end of year zonal 
examinations of above average. This is very encouraging both to students and stakeholders because education is the backbone of a bright future.

The following results of KCSE in Table 7 shows that for the last three years the county has been posting poor academic performance.

Table 7: K.C.S.E Performance in Tharaka-Nithi County for Last Three Years.

\begin{tabular}{lccccc}
\hline Mean Grade & Frequency & Percent & Year & Mean & SD \\
\hline E & 5 & 4.0 & & & \\
D- & 5 & 4.0 & & & \\
D+ & 27 & 21.6 & & & \\
D+ & 40 & 32.0 & & & \\
C- & 24 & 19.2 & 2015 & 4.181 & 0.309 \\
C & 8 & 6.4 & & 3.924 & 0.343 \\
C+ & 4 & 3.2 & 2016 & & \\
B- & 4 & 3.2 & & \\
B & 4 & 3.2 & & \\
B+ & 3 & 2.4 & & & \\
A- & 1 & 0.8 & Average & $\mathbf{4 . 0 0 0}$ & \\
\hline Total & 125 & 100.0 & & & \\
\hline
\end{tabular}

Source: TSC County Director's office, 2017

From the results in Table 7 indicate that majority (32\%) of the schools attained a mean grade of $\mathrm{D}+$. In addition, $12.8 \%$ of the schools attained a mean grade of $\mathrm{C}+$ and above. This implies that about one eighth of the school considered in the study had performance above average. However, $87.2 \%$ of the schools attained a grade below $\mathrm{C}+$. This indicates that there is need for schools administration to put in place a mechanism that would guarantee an improvement on the individual academic performance in KCSE of students. The overall mean score of schools performance was $4.00(\mathrm{D}+)$. This kind of academic performance, end up affecting the life of the student as well as the society economically. When students do not attain good grades to take them to the university, they end up not getting well paying jobs and as a result may not uplift the welfare of their families and society. This implies that there is need for stakeholders to reorganize and put in place mechanism that would guarantee improvement in academic performance in KCSE. In comparisons with end of year zonal examination, it was found that zonal performance was higher than that of KCSE for the same period. This could be caused by the fact that zonal exams covered only form one, two or form three course work and KCSE tested on the four years course work. In addition, students fear national examinations more than the internal examinations. The academic performance could be attributed to the kind of moderation done by the KNEC in Kenya Certificate of Secondary Examinations.

\subsubsection{Influence of Self-esteem on Students' Academic Performance}

The study sought to establish the influence of self-esteem on students' academic performance in secondary schools in Tharaka-Nithi County. Self-esteem was given in Likert Scale from 1=Extremely Low to 5=Extremely High. To test the association the following hypothesis was formulated:

Ho: There is no significant difference on the influence of self-esteem on students' academic performance in secondary schools in Tharaka-Nithi County, Kenya.

Hypothesis two was tested using Chi-square test. The results are displayed in Table 8 
Table 8: Influence of Self-esteem on Students' Academic Performance

\begin{tabular}{lccccc}
\hline & \multicolumn{3}{c}{ Performance } & & \\
\cline { 2 - 5 } Self-esteem & $\begin{array}{c}\text { Average } \\
\text { Below Average } \\
\text { (belween }+)\end{array}$ & $\begin{array}{c}\text { Above Average } \\
\text { B- \&C+) }\end{array}$ & Total & Chi-square Test \\
\hline Extremely Low & 0 & 2 & 0 & 2 & $\chi 2=13.92$ \\
Low & 2 & 1 & 2 & 5 & \\
Moderate & 8 & 18 & 17 & 43 & $\mathrm{df}=8$ \\
High & 29 & 50 & 65 & 144 & \\
Extremely High & 22 & 37 & 19 & 78 & Sig=0.084 \\
Total & 61 & 108 & 103 & 272 & \\
\hline
\end{tabular}

The cross tabulation was used to determine the influence of self-esteem on students' academic performance. The results show that there was no significant influence of self-esteem on students' academic performance, Chisquare value $=13.92, \mathrm{df}=8$ and $\mathrm{Sig}(\mathrm{P}$-value $)=0.084$ at $5 \%$ significant level. Since the $\mathrm{P}$-value $=0.0084$ is greater than 0.05 , this showed that self-esteem has no influence on students' academic performance. From these results the null hypothesis that there is no significant influence of self-esteem on students' academic performance was accepted (supported) at 5\% significant level.

These findings are contrary to a South African study by Carl (2005) on the influence of students' self-esteem on academic performance that found out that $88.5 \%$ of the student interviewed indicated the need for students' selfesteem to be uplifted for them to perform well academically. Students in Carl's study (2005) indicated that students' confidence level affected the learners 'academic performance positively or negatively. This means that facilitators must play a big role in boosting students' self-esteem for good academic results to be realized. These arguments are also supported by Mokua (2011) in his study on the role of the teacher in building the affective domain of the learners, when he points out that the learner's self-worth is crucial in determining their academic success.

However, according to Shulman (2012), in his study in America on the relationship between intellectual ability and excellence in academic performance, he notes that there is little or no relationship between intellectual ability and academic excellence. Another research by Akujohi (2006) conducted in Zambia points out that the level of self-efficacy among learners affects their academic performance, in that the higher the efficacy the better the performance.

Dondo (2005) observes that self-esteem may be helpful only in some job contexts. Laboratory studies have generally failed to find that self-esteem causes good task performance, with the important exception that positive self-esteem facilitates persistence after failure. People high in self-esteem claim to be more likable and attractive, to have better relationships, and to make better impressions on others than people with negative self-esteem, but objective measures disconfirm most of these beliefs. Narcissists are charming at first but tend to alienate others eventually. Self-esteem has not been shown to predict the quality or duration of relationships.

\subsubsection{Causes of Students poor Academic Performance}

The researcher sought information from the students, on the causes of students' poor academic performance in secondary schools. The information was analyzed by determining the percentages of the cause of poor academic performance. The results of the analysis are presented in Table 9. 
Table 9: Causes of Poor Academic performance in Secondary Schools

\begin{tabular}{lll}
\hline Cause & Frequency & $\%$ \\
\hline Laziness among students & 269 & 94.7 \\
Poor coverage syllabus & 252 & 88.7 \\
Availability of drugs & 232 & 81.7 \\
Expecting leakage in exams & 208 & 73.2 \\
Fear of exams & 201 & 70.9 \\
Lack of enough revision materials & 198 & 69.8 \\
Mis-interpretations of questions & 193 & 67.9 \\
Discouragements from others & 172 & 60.7 \\
Lack of follow up at home & 165 & 58.2 \\
Absenteeism from school & 155 & 54.6 \\
\hline
\end{tabular}

According to Table 9, the most common cause of students' poor academic performance as reported by most of the respondents was laziness among students $(94.7 \%)$, poor coverage of the syllabus $(88.7 \%)$, availability of drugs $(81.7 \%)$, expecting leakage in exams $(73.2 \%)$, fear of exams $(70.8 \%)$ and lack of enough revision materials $(69.7 \%)$. In general, all the above causes of poor academic performance were rated $50 \%$ and above. This shows the need for the school administration to address the above causes in order to improve academic performance of students in secondary schools.

According to Mutuma(2012) in his study in Nigeria on the relationship between discipline and excellence in academic performance, he notes that students' discipline is crucial in them achieving academic excellence. That means students who are lazy, always absent from school and involve themselves in drugs perform dismally. Dondo (2005) points out that many factors affect students' academic performance and among them are teachers' characteristics, students' characteristics and the general environment of the school. Also, Messies (2006) found that there are other factors that lead to poor academic performance among student in secondary schools such as school facilities, ability of the learner, gender bias and stereotype, parental and family attitudes, gender attitude and interest.

\subsection{Qualitative Data Analysis}

Deputy Head-teachers felt that most of the schools were average in academic activities including exams. Most of the schools had taken students to the county level in Drama and music. A few were also good in games and sports. In examinations, most of the respondents pointed out that most students scored around $\mathrm{C}+$. Although there were a few cases of $\mathrm{C}$ and $\mathrm{D}+$. A number of day schools were presented to mostly score means of $\mathrm{C}+$. The extra county schools and National schools were portrayed to perform better than day schools. However, day schools also had cases of grades above $\mathrm{C}+$.

Heads of Curriculum felt that the performance of students in academic activities including exams was average. Most students were rated to score $\mathrm{C}+$ and above but a few cases of $\mathrm{C}$ and below were not an exceptional. Grades of A and A- were rare in county boarding and Day schools. This was attributed to the low entry requirement of the students.

Heads of Guidance and Counseling also felt that the performance of students was average. There were more of the $\mathrm{C}+$ and above grades in Extra County schools and National schools. However, the schools would not lack cases of the grades below average. A number of schools had reached the regional in music. Only a handful of schools participated in Dram festivals.

\subsection{CONCLUSIONS AND RECOMMENDATIONS 5.1 Conclusions of the Study}

Based on the findings of the study, the following conclusions were drawn 
i. The study found that self-esteem had insignificant influence on students' academic performance in secondary schools in Tharaka-Nithi County, Kenya. This indicates that high self-esteem does not necessarily influence students' academic performance in secondary school. However, the respondents agreed that, selfesteem plays a critical role in academic activities in secondary schools.

ii. The study found that the overall mean score of academic performance in zonal examinations was approximately 8 (B-). This implies that the students had achieved the academic performance of above average in the zonal exams. This is very encouraging both to students and stakeholders because education is the backbone of a bright future. Although the mean score of student's academic performance in KCSE was very low, that is $4(\mathrm{D}+)$ which indicates the need for student's self-esteem to be improved for good grades to be realized among secondary school students in Tharaka-Nithi County, Kenya

iii. The study established that self-esteem of students could be improved through guidance and counseling, interaction with other schools, participation in symposiums, strengthening peer counseling, supporting needy students, motivating students by accepting them and rewarding where necessary. Furthermore, the respondents pointed out the importance of strengthening their spirituality and beatitudes, promoting their reading culture to gain more knowledge on how to improve self-esteem, engaging motivational speakers, practicing living consciously and regular reinforcement and talks on self-awareness.

\subsection{Recommendations of the Study}

Since the respondents agreed that, self-esteem plays a critical role in academic activities in secondary schools, there is need for school administration to focus on life skills education to boost the performance of students in academic related activities in secondary schools.

\section{REFERENCES}

Branden, N. (2008). Heroic Potentials of Human Name: Honouring the self personalIntegrity.Los Angeles: Jeremy P. Tarcher, inc.

Branden, N. (2009). The Psychology of Self-esteem. New York. Random Publishers.

Dondo, M. (2005). Guidance \& Counselling for Schools and Colleges. Nairobi: Migori School of Guidance and Counselling.

Douglas, M.R. (2009). How to Win with Positive Self-esteem. New Delhi: Pauls press. EbonyiState Universal Basic Education Board (2015). School nominal roll. Abakaliki: the Statistics Department.

Douglas, C. (2010). Effects of Self-esteem on Students Discipline. Lagos; Nigeria.

Gichinga, E.M. (2005). Youth Counselling. A Counseling Guide. Nairobi: GEM Counseling Services.

Greeno, J.G. (2001). Students with Confidence, Competence and Accountability: Affording intellective identities in classrooms New York: The College Board

Guindon, M.H. (2002). Toward Accountability in the Use of the Self-Esteem Construct. Journal of Counseling \& Development, 80(2) , 204-214.

Heaven, D.E. (2005). Allow the Youth to Grow in All Ways. Englewood Cliffs, N.J: Prentice- Hall.

James, W. /(2004). Literary Domains of Self-esteem. New York: Bantam books.

Kholonde (2009). Improving Academic Performance of Secondary School Students. Smithsonian Institute Press: Lodon.

Kenya Institute of Education (2003) Guidance and Counseling - Teacher's handbook . KIE, Nairobi

Kombo, D.K and Tromp, D.L. (2006). Proposal and Thesiss writing. An Intoroduction. Nairobi : Paulines Publication Africa.

Kothari, C.R. (2014). Research Methods and Techniques. New Delhi : New Age International (p) Ltd.

Messies, C. (2006). Learners and Academic Performance. New York: OxfordUniversity Press .

Miller, H.P. (2002). The Power and Limits of a Vision New York. The Free Press.

M.O.E (2012). Elimu News .A news letter of the MOE, Issue No. 7.Nairobi: MOE 
Mugambi, D. J. (2010). Building Self Confidence and Self-Awareness among the Youth. M.ed Thesis. Moi University

Mugambi, N. (2014). Impact of Self-Esteem on Learners Academic Performance at Class room Level in United States. International Journal of Educational Research. Rehttp:/www.doi:10:10:10lb/j.ifer.2011.06.004.

Mutuma (2007). Building and Understanding Self-Concept among the Youth. Nairobi.

Mutuma, E.K. (2010). Influence of Leadership Styles on Students Academic performance. Lagos Nigeria: New Educational Books Publishers

Orodho, A.J. (2003). Essentials of Educational and Social Science Research Methods: Masola publisher.

Petro, D.C (2007) Self worth, A matter of self. Here's life Publishers.

Robert, B.B.(2008). Self-Concept Development and Education. East Africa:Rinehart and Winton Ltd, Dorset Press.

Robert (2005). Theory and Practice of Education. Nairobi - East Africa Ed Problems Ltd.

Rosenberg, M. (2008). Beyond Self-Esteem: The Neglected Issues in Self-concept Research.Paper presented at the annual meetings of the ASA.

Rosenberg, M. (2008). Conceiving the Self. Basic Books.

Rosenberg, M. (2008). Conceiving the self: Krieger:Malabar,Fl.In internet source; File://A: $\mid$ Rosenberg\%20 scale $\% 20$ of $\% 20$ self-esteem.htm.

Silverstone, P. H., \&Salsali, M. (2003). Negative Self-esteem and Psychiatric Patients: Part I- The Relationship Between Negative Self-esteem and Psychiatric Diagnosis. Annals of General Psychiatry, 2(1), 2.

Susan, K. (2009). Effectiveness of Self-esteem on Leadership Styles. Nairobi: Kenya

Susan (2009). Needs Assessment and utilization of counseling services Among Students in Kenya Public University. Unpublished PhD Thesis. Chuka University.

Susan, W. (2012). Developing in Essential Schools. Coalition of Essential Schools. London: Praeger

UNESCO (2015). Educational for All Global Monitoring Report. 2000-15 at Unescodoc. Unesco. Retrieved on 3/5/15 from org/images/0023/00222322/2322 use.pdf.

UNESCO. (2000). Nigerian Educational Research and Development Council. (NERDC) Yaba, Lagos.

Viktor, G. (2012). The Self-Concept. Annual Review of Sociology, 8:1-33.

Viktor, G., \& Schwalbe, M.L. (2012). Beyond the Looking-glass Self: Social Structure and Efficacy-Based SelfEsteem. Social Psychology Quarterly, 46:77-88. 